P4.034 EFFECTS OF PARTNER DISCLOSURE ON CLINICAL OUTCOMES AMONG HIV INFECTED ADULT INITIATING ART

doi:10.1136/sextrans-2013-051184.0932

'R S Ngomoa, ${ }^{2} \mathrm{~J}$ Njoroge, ${ }^{1} \mathrm{~J}$ Thiga, ${ }^{2} \mathrm{C}$ McGrath, ${ }^{2} \mathrm{M} \mathrm{H}$ Chung, 'M Attwa, ${ }^{2} \mathrm{~N}$ Yatich ${ }^{1}$ Coptic Hope Center for Infectious Diseases, Nairobi, Kenya; ${ }^{2}$ University of Washington, Seattle, WA, United States

Background Disclosure of HIV status can influence clinical outcomes. Disclosure leads to social support, improved adherence and positive living which may affect immune reconstitution. Data on the effect of disclosure on immune reconstitution is limited. The objective of this study was to assess the effect of partner disclosure at ART initiation on immune reconstitution.

Methods A retrospective cohort study was done among adults with a spouse/steady partner, initiating ART within 3 months of enrollment at Coptic Hope Center between January 2009 and June 2010. Immune reconstitution was defined as 30\% increase in CD4 count (cells $/ \mathrm{mm}^{3}$ ) following ART, and disclosure as self-reported disclosure of HIV status to spouse/steady partner at ART initiation. Data was obtained from patient records collected routinely for clinical care. The association between disclosure and immune reconstitution was assessed using Kaplan-Meier survival curve and multivariate Cox proportional hazards model adjusted for covariates univariately associated with immune reconstitution $(P \leq 0.10)$. Results Among 543 clients initiating ART within 3 months of enrollment, 467 (86\%) had disclosed their status to their spouses/ steady partner. Median CD4 count at disclosure was 143 cells $/ \mathrm{mm}^{3}$. At month $12,68 \%$ of those who had disclosed had attained immune reconstitution compared to $48 \%$ of those who had not disclosed. By 24 months, $80 \%$ of adults in the disclosed group had reconstituted their immune status compared to $60 \%$ of those who had not disclosed. Adults with higher baseline CD4 count were less likely to attain immune reconstitution while adults who had disclosed their status to their spouse/steady partner were $63 \%$ more likely to attain immune reconstitution compared to those who had not disclosed $(p<0.05)$. There was a trend that higher education was associated with immune reconstitution.

Conclusions Disclosure at ART was significantly associated with immune reconstitution. HIV disclosure status may be essential in improving the clinical outcomes of clients.

\section{P4.035 DRUG USE AND STI IN A DUTCH COHORT OF SWINGERS}

doi:10.1136/sextrans-2013-051184.0933

'L W L Spauwen, ${ }^{1,2}$ A M Niekamp, ${ }^{1,2} \mathrm{C}$ J P A Hoebe, ${ }^{1,2}$ N H T M Dukers-Muijrers. 'Department of Sexual Health, Infectious Diseases and Environmental Health, South Limburg Public Health Service, Geleen, The Netherlands; 'Department of Medical Microbiology, School of Public Health and Primary Care (CAPHRI), Maastricht University Medical Centre (MUMC+), Maastricht, The Netherlands

Background Recently, swingers are classified as an emerging highrisk group for STI. A well excepted explanation is that swingers have multiple sex partners, concurrent partnerships and engage in high risk behaviour enabling rapid spread of STI. The present study assessed the prevalence of drug use while swinging and the contribution of drug use to STI risk.

Methods In our cohort study we included couples who self identified as swingers and visited the STI clinic in Limburg (2009-2012). Swingers (median age 45 years) filled in a self administered questionnaire to assess their sexual and drug use behaviour in the past 6 months. Using chi-square test associations with drug use were assessed.

Results Of 294 swingers, 49\% were female, 48\%( $n=140)(49 \%$ in men; $46 \%$ in women) reported drug use (other than alcohol or erectile dysfunction drugs) while swinging.
Top 5 drugs used were laughing gas (87\%), XTC (86\%), GHB $(79 \%)$, cannabis $(60 \%)$ and poppers $(33 \%)$. Overall, alcohol was used by $46 \%$. Of men $63 \%$ and of women $6 \%$ used erectile dysfunction drugs of which Camagra was most reported. Multiple drug use was reported by $90 \%$ of the users. Most common combinations include GHB and XTC (67\%), XTC and erectile dysfunction drugs (38\%), and alcohol and erectile dysfunction drugs (29\%). Multiple drug use was associated with low education, swinging at home party's, swinging more than 2 years, swinging more than 4 times in the last 6 months, more than 5 partners and group sex. Assessment of association with STI is ongoing.

Conclusion Prevalence of drug use in swingers is high. It has been shown that drug use is associated with increased high risk sexual behaviour in different groups and we show this is also the case in swingers who use multiple drugs. Whether drug use is associated with STI will be determined.

\section{P4.036 CONDOM USE AMONG FEMALE SEX WORKERS (FSWS) INCREASED THROUGH DROP IN CENTER (DIC) BASED SERVICE DELIVERY APPROACH IN BANGLADESH}

doi:10.1136/sextrans-2013-051184.0934

'Z Hossain, ${ }^{1} \mathrm{~F}$ Sultana, ${ }^{1} \mathrm{M}$ Amin, ${ }^{2} \mathrm{Y}$ Siddiqua. ${ }^{1}$ HIV Program, Save the Children in Bangladesh, Dhaka, Bangladesh; '2Ac Nielsen, Bangladesh, Dhaka, Bangladesh

Background The HIV prevalence in Bangladesh remains low $(<1 \%)$ among FSWs. Since June 2008, with the funding supports from the Global Fund, Save the Children gradually scaled up essential services for approximately 28,600 FSWs in 51 districts through 100 Drop in Centers and 10 outreach offices. DICs provide FSWs with behavioural change education, free condoms, STI \& general health service and effective referral services including voluntary counselling and testing (VCT) and maternal \& child health (MCH) services. Through the programme, a total of $28,712,708$ condoms were distributed among FSWs for free and 37,318,497 condoms were purchased by FSWs through social marketing.

Methods The Midterm Survey, 2012, a cross sectional study was conducted using robust multifarious analytical tools (both advanced quantitative and qualitative techniques) to assess the progress made by the Rolling Continuation Channel (RCC), Phase-I (Dec'09Nov'12) implemented by Save the Children. A total of 1,729 FSWs (street, hotel and residence based) were interviewed for the survey. Results Overall, 85\% FSWs had regular clients during the most recent week. Among them, 93\% reported condom use during the last sex act with the client. on the other hand $77 \%$ of had new clients in last week among them, 93\% reported use of condom during the last sex act with their new client. Combining all together, condom use rate has increased from $66.7 \%$ (Source: UNGASS Country Progress Report, 2008) to 95.5\% in the Midterm Survey, 2012.

Conclusion Condom use is vital to prevent HIV among FSWs. Although condom use rate is high among the FSWs, strong motivational activities including peer education should be continued for the FSWs to keep the current condom use rate.

\section{P4.037 USE OF CELL PHONE DIARIES TO UNDERSTAND RISK CONTEXTS OF SEXUAL EVENTS AMONG FEMALE SEX WORKERS}

doi:10.1136/sextrans-2013-051184.0935

'A M Roth, ' $2 \mathrm{D}$ J Hensel, ' $\mathrm{J}$ Gunn, ${ }^{2} \mathrm{~J} D$ Fortenberry, 'R Garfein, 2 J N Arno, 2 S E Wiehe. 'University of California San Diego, La Jolla, CA, United States; 'Indiana University, Indianapolis, IN, United States

Background Data collection using mobile technologies, such as cell phones, allows more frequent and real-time data collection and is less prone to recall bias. We describe the feasibility of using twice daily cell 